\title{
POSSIBILIDADES DE SIGNIFICAÇÃO DO TIPO: CONSIDERAÇÕES SEMIÓTICAS E HISTÓRICAS SOBRE OS SIGNOS TIPOGRÁFICOS
}

\author{
Luís Morici \\ Universidade do Estado de Minas Gerais \\ luisecmorici@gmail.com \\ Sérgio Antônio Silva \\ Universidade do Estado de Minas Gerais \\ sas.sergiosilva@gmail.com
}

Resumo: Para se compreender a produção de significado no tipo e no design tipográfico, é proposto um método de divisão, em diferentes níveis de significação, dos signos que constituem esse objeto. Em primeiro lugar, o tipo é estudado enquanto suporte de comunicação pertinente à linguagem verbal. $\mathrm{O}$ arquétipo de caracteres se revela como base imutável para o desenvolvimento de novos tipos. Em seguida, e em oposição, o aspecto visual da tipografia é trazido à tona para maior exploração. É nessa abordagem como signo visual que o tipo pode ser compreendido como produção cultural capaz construir sistemas de conotação. Exemplos de conotação são oferecidos, tanto na prática tipográfica contemporânea, quanto na história das transformações das formas tipográficas. A história revela sua relação íntima com os sistemas de conotação, na medida em que sistemas denotados já existentes na cultura servem de guia para as formas dos tipos que vêm a ser projetados. Essa asserção, bem como a utilização da semiótica como um todo diante do objeto proposto, podem servir para ajudar no controle de resultados relacionados à significação, dentro de um projeto que envolva tipografia.

Palavras-chave: design, tipografia, semiótica, história

\begin{abstract}
To understand the production of meaning provided by type and by the act of type designing, it is proposed a method of dividing the signs that constitute this object into different levels of signification. Firstly, type is studied as a support for communicating contents related to verbal language. Character archetype is seen as an irremovable base in the development of new typefaces. Then, in opposition, the visual aspect of type is highlighted towards further exploration. In this visual approach, type can be understood as a cultural production that is able to build systems of connotation. Examples of connotation are exposed regarding contemporary typographic practice, as well as regarding history of change in typographic form. History reveals close relation with systems of connotation, considering that preexisting denoted systems found in culture guide type forms to be designed. This assertion, as well as the use of semiotics as a
\end{abstract}


whole towards the proposed object, may help controlling results that relate to signification inside a typography project.

Keywords: design, typography, semiotics, history

\section{INTRODUÇÃO}

Na expressão gráfica de um tipo encontram-se vários níveis de significado. Em primeiro lugar, considerada a tipografia ocidental, cada glifo de um tipo se refere a um caractere tradicional do alfabeto latino. Mas, mais que significarem caracteres deste sistema, os tipos têm outros modos de expressão inscritos em si, e cabe aqui uma investigação acerca dessas possibilidades. São possibilidades necessárias, já que tipografia nunca é apenas texto: é também imagem e, como tal, apresenta signos típicos da expressão imagética.

A pesquisa nesse sentido revela diversas facetas da relação humana com este instrumento. Para quê determinado tipo é utilizado; o que ele tem a dizer sobre si na complexa trama da comunicação; o quão é expressivo como imagem ou como suporte de texto - muitas são as questões que a presente tarefa, dentro de suas próprias limitações, ajuda a esclarecer. É neste sentido que, com a sua realização, novas possibilidades de compreensão da transformação das formas tipográficas surgem, e, com elas, maior domínio dos resultados de um projeto de design tipográfico.

Por isso, este trabalho se lança à meta de elucidar as significações - ou, ao menos, parte delas - na tipografia. Primeiramente, é realizada uma análise da linguagem. Trata-se esta do primeiro sistema com o qual a expressão tipográfica se relaciona. Sem a linguagem não há a razão de ser do tipo. Seguindo da expressão verbal até a forma de um dado tipo, diversos são os sistemas semióticos concatenados que merecem atenção, mas apenas o essencial para o objetivo aqui determinado será mencionado. Em seguida, parte-se para a exploração do tema específico da dicotomia entre tipo como signo verbal e signo visual. Com o conceito de "conotação" delimitado, exemplos da história da tipografia podem ser compreendidos dada a pesquisa acerca da significação na tipografia.

\section{TIPOGRAFIA, SIGNO E LINGUAGEM}

O ser humano compreende o mundo pela mediação da linguagem. Não existe a possibilidade de conhecimento de um objeto, qualquer que seja, sem que a linguagem se estabeleça, em uma complexa trama na qual coexistem os signos. Historicamente, tem-se que o ato gestual de poder comunicativo foi complementado pela fala, para que depois surgisse a escrita. Isso não quer dizer que a escrita seja apenas o registro visual de algo maior - qual seja - a própria fala. No cenário em que se estabelece e se conceitua a própria linguagem, a fala e a escrita se complementam. Também não quer dizer que esta última deriva unicamente da oralidade: a gênese da escrita é dupla, e encontra-se em ambas as comunicações verbal e imagética (ARBEX, 2006).

Dentro da tradição filosófica ocidental, a oposição entre fala e escrita é um exemplo de casos em que se percebe uma certa polarização conceitual, em que um dos conceitos do binômio adquire uma aura de real e elevado - neste caso, a fala - em oposição ao outro, mundano, falso ou com atributo de mera cópia - a escrita. 0 
mesmo ocorre para dicotomias como representação e realidade, natureza e cultura, mente e corpo, entre muitos outros. Quando Derrida (apud LUPTON; MILLER, 2009) introduz na academia o conceito de "desconstrução", a partir de 1967, essas dicotomias têm sua bases abaladas. Pelo que roga o pensamento associado à desconstrução, a suposta hierarquia entre um conceito e outro perde lastro. No mesmo sentido, questiona-se a sugerida superioridade da fala sobre a escrita. Afinal, tem-se que a escrita possui o poder de permear a memória e o espírito humano, invadindo a fala e até mesmo o pensamento (LUPTON; MILLER, 2009). A escrita não é mera cópia incompleta da fala, é forma ativa de representação.

Para Saussure (2006) - que mesmo considerada a desconstrução, nos é essencial aqui ${ }^{1}$ - a língua funciona por meio da diferença. Um signo é composto por relação inicialmente aleatória entre seu significante, ou se plano de expressão, e seu significado, ou plano de conteúdo. Não há nada intrínseco, natural ou apriorístico a esta relação que justifique seu o funcionamento como signo. Este opera em seu papel de comunicação na medida em que é diferente de outros signos - a expressão "cavalo" não é o mesmo que a expressão "zebra", por exemplo. Partindo da fala à escrita, para se restringir à língua portuguesa, há significantes que revelam diferentes significados, indetectáveis pela fala, como no caso de "concerto" e "conserto". A escrita também se apresenta como imprópria para a totalidade da expressividade linguística, por outro lado: é incapaz de incorporar, por exemplo, a ênfase na pronúncia de uma palavra dentro de uma frase, e essa ênfase por si só pode alterar o significado do que se quer dizer.

Para se compreender a operação do instrumento da escrita, é preciso distinguir a ideografia da fonografia. Os ideogramas antecedem historicamente a invenção de alfabetos, capazes estes de servir como instrumento de uma escrita fonética, ainda que aqueles perdurem em determinados idiomas contemporâneos. Nos idiomas que se valem da transcrição fonética, entretanto, a leitura treinada não se realiza pela identificação letra a letra, mas sim de palavras inteiras. É o desenho destas que possibilita, portanto, a leitura, de modo que é válido afirmar que, ao lugar de ideogramas, idiomas baseados em transcrições fonéticas são lidos por meio das palavras enquanto "unidades ideo-fono-gráficas" (MANDEL, 2006, p. 79). Aqui é crucial identificar a importância do desenho da palavra como um todo, razão pela qual forma e disposição das letras não deixam de ser de menor importância para estudos de temas amplos como a linguagem e a cultura.

Entretanto, antes de se entrar na seara das formas tipográficas, cumpre defender as letras enquanto signos. As letras como hoje as conhecemos compõem um sistema alfabético, e têm sua origem remota nos ideogramas. São o resultado formal de estilização de desenhos inicialmente figurativos. Se, ainda como figurações, identificavam palavras inteiras, passaram, já sintetizadas, a representar o primeiro som da palavra em questão, pelo sistema de acrofonia. Justapostos, os desenhos seriam capazes de formar qualquer palavra a partir da reconstrução dos fonemas em sua forma visual. Cada letra do alfabeto latino carrega, portanto, uma longa e lenta história de transformação. A letra é requisito primeiro para a forma dos tipos, e destitui da atividade de design tipográfico a possibilidade de total originalidade. Nenhum tipo desconsiderados os dingbats, que não comunicam propriamente um conteúdo de

\footnotetext{
Saussure aborda a linguagem pelo viés tipicamente estruturalista, ao passo que a desconstrução pode ser considerada pós-estruturalista.
} 
natureza verbal ${ }^{2}$ - pode ser inteiramente original, já que parte desde o início, para o desenvolvimento de seus caracteres, de formas construídas ao longo de milênios: as formas das letras dos alfabetos e as formas dos demais caracteres. A obediência a essas formas, ou "arquétipos de caracteres" (FRUTIGER, 2007, p. 170), tem impacto direto sobre a legibilidade de um tipo. Ou seja, quanto mais próximos dos arquétipos são os glifos projetados, mais identificáveis são enquanto suporte de texto.

\section{SIGNO VISUAL E SIGNO VERBAL NA TIPOGRAFIA}

Os caracteres de um tipo, como visto, carregam consigo um desenho-base que Ihe confere poder de significação linguística. Entretanto, por terem caráter inerentemente visual, portam também um sistema de significação que é típico do campo da comunicação imagética. A tipografia, assim, serve como suporte da escrita e como objeto para ser visto. É nela que escrita e comunicação visual se encontram inseparáveis (VAN LEEUWEN, 2006). Por isso, é dito que na tipografia existe a "sobreposição entre signos visuais e verbais" (GRUSZYNSKY, 2008: 17), ou "uma conjugação do duplo movimento de olhar e ler" (MARTINS, 2007: 60). Este aspecto de ambiguidade já foi objeto de extenso debate, e cabe aqui a exposição e análise do que for cabível para a compreensão das significações da tipografia.

Apesar de não ser o caso para muitos dos debatedores dessa questão, pretende-se compreender a tipografia em sentido amplo, como toda manifestação da escrita, e não apenas o que tange a confecção livros ou documentos, ou o que se produz com tipos móveis, tipos de fotocomposição ou digitais. Para tal, devem ser expostas ao menos três funções básicas da escrita (MANDEL, 2006): monumental, livresca e usual. Na função monumental se expressa o poder púbico, como, por exemplo, nas lápides romanas ou nas fachadas de edifício do governo, hoje em dia. A escrita livresca se dedica à propagação de ideias, e pertence ao domínio cultural e intelectual. Por último, a função usual, ou privada se relaciona às mais diversas atividades do cotidiano particular, como a produção de notas e a correspondência. Até o advento da máquina de escrever, a função usual restringia-se à escrita a mão, e não se inseria no domínio forma de reprodução automatizada que compreende o tipo.

É na função livresca que se concentra majoritariamente o debate sobre a simultaneidade do aspecto verbal e do aspecto visual tipográficos. Nela parecem se concentrar dicotomias próximas, a saber: entre tipos visíveis e invisíveis (GAUDÊNCIO JUNIOR, 2004); entre tipos para ver e tipos para ler (MANDEL, 2006) e entre tipografia clássica e tipografia experimental (ROCHA, 2012). A dita "boa" tipografia já foi comparada a um "cálice de cristal" (WARDE, 1956, p. 18), por portar de bom grado assim como o faz uma taça translúcida que recebe um bom vinho - o conteúdo escrito, de modo a não the impor obstáculo quando da apreensão do leitor. Em sentido semelhante, Bringhurst (2008, p. 23) fala em "estátua transparente": a tipografia ideal chama a atenção antes de ser lida, para, depois, ao momento da leitura, se livrar da atenção dedicada a si própria em favor da mensagem escrita.

Contrapondo a tipografia invisível, totalmente subjugada à função de suporte textual, existe a tipografia para ser vista. Essa função torna-se especialmente notável com as vanguardas do século $\mathrm{XX}$, a começar pelo futurismo. A poesia de Tommaso comunicar.

No mesmo sentido, Barthes (2012) considerada que a fala sem a língua não cumpre a função de 
Marinetti conferiu materialidade à palavra (CASTELACCl; SANVITALE, 2000), e a libertou de forma brusca das amarras convencionais da função verbal. Posteriormente vieram o dadaísmo, o cubismo o construtivismo e outros movimentos que desafiavam, nos seus respectivos modos, tal função. A vanguardas abriram caminho a aventuras contemporâneas de desconstrução, nas quais textos devem ser por vezes até mesmo arduamente decifrados para que sejam lidos.

\section{CONOTAÇÃO}

Superada a função puramente verbal da tipografia, pode-se partir ao exame da expressão visual. É em seu aspecto gráfico que a compreensão da significação tipográfica pode se valer, como auxílio, de conceitos como o de "conotação". A depender de autores, o que se entende por conotação pode produzir divergências. No presente estudo o termo é entendido como aquele descrito por Van Leeuwen (2005; 2006). Para a abordagem do fenômeno da conotação, o autor utiliza o conceito como trabalhado por Barthes (2001) em sua empreitada acerca dos mitos. Isto considerado, tem-se que, para Barthes $(1990,2012)$, a conotação é concebida pela transposição de um signo de um sistema para outro. Se, na semiótica, um sistema é composto por uma expressão e por um conteúdo correspondentes, a conotação ocorre quando todo um sistema é inserido como expressão de um segundo sistema. Ou seja: o plano de expressão de um sistema conotado é composto pelo plano de significação denotado (quadro 1). Por isso, na conotação, um signo é transferido e carrega consigo significados para um novo contexto.

Quadro 1 - Relação entre denotação e conotação.

\begin{tabular}{|l|l|l|l|}
\hline Sistema conotado & \multicolumn{2}{|l|}{ Expressão } & Conteúdo \\
\cline { 1 - 2 } Sistema denotado & Expressão & Conteúdo &
\end{tabular}

Fonte: Adaptado de BARTHES, 2012, p. 114

É possível explorar exemplos no design tipográfico, seguindo a aplicação do conceito de conotação para este campo, da mesma forma que o faz Van Leeuwen (2005; 2006). No caso do tipo Brandon Printed Two (figura 1), desenvolvido por Hannes von Döhren, tem-se a forma de uma san serif com detalhes de textura que se assemelham àqueles produzidos no processo da prensa com tipos de madeira. Por esta razão, o emprego da respectiva fonte digital porta consigo um significado de rusticidade, deslocada do contexto original da técnica de tipos móveis - em especial daqueles empregados nas incipientes produções gráficas comerciais e publicitárias do século XIX. Nesse tipo, portanto, há de imediato a denotação do sistema que comporta a leitura de caracteres específicos do alfabeto latino, mas as formas específicas conotam o sentido do que é artesanal, rústico e imperfeito.

\section{BRANDON PRINTED}

Figura 1 - Tipo Brandon Printed Two.

Fonte: www.myfonts.com 


\section{CONSIDERAÇÕES EM HISTÓRIA DA TIPOGRAFIA}

A história da tipografia é permeada majoritariamente por com conservadorismo das formas. Entretanto, lentas transformações ao longo de um vasto período apontam para a mutação formal geral dos tipos. Com base nos instrumentos já expostos, entende-se possível o estudo dessa transformação a partir da semiótica. Ou seja: a análise por meio de um modelo baseado em processos de significação pode lançar luz sobre a história das formas tipográficas.

Assim, parece ser o caso de compreender o conservadorismo e a lenta transformação tipográfica como aspectos de um processo baseado na conotação. Esta conotação pode ser percebida em determinados momentos históricos em que a técnica de produção tipográfica muda, sem que a forma acompanhe tal mudança. Como afirma Mandel (2006), as tranformações da técnica em tipografia não afetam sua forma, esta é reflexo do espírito do homem em seu contexto histórico-cultural.

Para encontrar processos de conotação, exemplos se tornam úteis. Quando Gutenberg imprimiu a Bíblia de 42 linhas, valeu-se de tipos móveis o mais próximos o possível da caligrafia em voga, de modo a simular uma obra escrita à mão, familiar ao leitor. Trouxe para sua técnica inovadora, a prensa, elementos formais de um outro contexto, de modo que a textura gótica da Bíblia conotasse toda a tradicional relação com a pena chata. Este instrumento caligráfico, embora não estivesse presente na confecção do texto da Bíblia de 42 linhas, estava simbolicamente inserido no sistema novo, incutido nas forma através da morfologia do eixo, das hastes verticais dominantes, dos desenhos de entradas e saídas de pena presentes em cada tipo móvel esculpido em aço e fundido em chumbo.

Conotações podem ser encontradas não apenas na manutenção das formas, mas na mudança no espírito e na cultura de uma determinada época, cujos reflexos se encontram na tipografia, sem que hajam mudança bruscas de técnica. Um exemplo seria a obra tipográfica moderna de Giambattista Bodoni, desenvolvida por volta de 1790. Para que fosse possível a mutação dos tipos humanistas para os modernos, ocorreu uma passagem pelo que se denomina "estilo transicional", que abarca os trabalhos de Fournier, de Grandjean - com sua "Romana do Rei" - e de Baskerville. Considerada essa gradual transformação histórica, tem-se que dois fatores de mudança cultural levaram à obra de Bodoni: a crescente busca pela racionalização das formas, impulsionada pelo lluminismo, e a construção geométrica dos tipos, levada a cabo pelo raciocínio matemático da Revolução Industrial em curso. Interessa, aqui, explorar o segundo fator: a construção de cada caractere com base não na herança de caligrafia, mas na lógica do pensamento mecânico aplicado à formação do tipo por meio de módulos intercambiáveis. É de se notar que mesma época em que Bodoni desenvolvia seus tipos com base nesse sistema, Eli Whitney elaborava a fabricação de armas de fogo com partes intercambiáveis, nos Estados Unidos (MEGGS, 2009). Para a construção do novo tipo de Bodoni, com contrastes proeminentes, a técnica de fundição de impressão tinha se tornado mais precisas, mas foram apenas facilitadoras, e não determinantes. Tais formas do tipo Bodoni, assim, conotam os primeiros passos da era da mecanização e da produção em massa, conforme percebida pelos seus contemporâneos. 


\section{CONCLUSÃO}

A tipografia é signo verbal e visual. É a partir da linguagem que se pode compreender a sua faceta verbal, mas é pelo aspecto imagético que cada face de tipo se difere da outra. Na imensa diversidade de tipos que hoje existem, tem-se que sua razão de ser é, para além do ímpeto criativo individual, a capacidade de expressão que cada obra oferece de diverso, de novo, de mais próximo de um ideal, qualquer que este seja. E pela análise de sucessivas criações tipográficas em função da História, a conotação, como entendida dentro da semiótica, se apresenta como conceito extremamente útil.

Pelos exemplos vistos de conotação através da história da tipografia, é possível concluir que o descolamento entre a técnica de desenvolvimento ou de reprodução e a forma possui estreito laço com o aspecto conotativo das formas dos tipos em seu desenvolvimento temporal. Esse descolamento se evidencia por duas vias: pelo caso em que uma nova técnica não enseja, de imediato, uma nova forma, em um segundo caso, em que novas formas surgem sem a transformação técnica como causa. Quando ocorre o primeiro, o tipo em sua nova técnica conota a técnica antiga; quando ocorre o segundo, o tipo conota um fator cultural novo, de relevância para o desenvolvimento dos ofícios e faculdades humanas.

Inserir a produção tipográfica em uma análise semiótica é um passo rumo a uma compreensão teórica incipiente acerca dos mecanismos pelos quais os tipos produzem significado. Esta abordagem teórica que se forma é capaz de fornecer insumos para a atividade projetual cotidiana, seja no design com tipos, a exemplo do design editorial, seja na design de tipos, operação a qual se dedicam os tipógrafos.

\section{REFERÊNCIAS}

ARBEX, Márcia. Poéticas do visível: uma breve introdução. In: (org.). Poéticas

do visível: ensaios sobre a escrita e a imagem. Belo Horizonte: Programa de PósGraduação em Letras: Estudos Literários, Faculdade de Letras da UFMG, 2006.

BARTHES, Roland. A retórica da imagem. O óbvio e o obtuso. Rio de Janeiro: Nova Fronteira, 1990.

BARTHES, Roland. Elementos de semiologia. 19 ed. São Paulo: Cultrix, 2012.

BARTHES, Roland. Mitologias. 11 ed. Rio de Janeiro: Bertrand Brasil, 2001.

BRINGHURST, Robert. Elementos do estilo tipográfico. São Paulo: Cosac Naif, 2008.

CASTELACCI, Claudio; SANVITALE, Patrizia. Tipografia em liberdade. Tupigrafia, São Paulo, n.9, p. 108-117, mai, 2000.

FRUTIGER, A. Sinais e símbolos: desenho, projeto e significado. São Paulo: Martins Fontes, 2007.

GAUDÊNCIO JUNIOR, Norberto. A herança escultórica da tipografia. São Paulo: Rosari, 2004.

GRUSZYNSKI, Ana Cláudia. Design gráfico: do invisível ao ilegível. São Paulo: Rosari, 2008. 
Design gráfico, tecnologia e mediação. In. Congresso Brasileiro de Ciências da Comunicação (22. : 1999 : Rio de Janeiro). [Anais. .]. Rio de Janeiro : Intercom, 1999.

LUPTON, Ellen; MILLER, J. Abbott. Desconstruction and graphic design. 2009.

Disponível na internet por http em: <http://elupton.com/2009/10/deconstructionand-graphic-design> Acesso em 16 out 2015

MEGGS, Phillip B.. História do Design Gráfico. São Paulo: Cosac Naif, 2009.

MANDEL, L. Escrita: espelho dos homens e da sociedade. São Paulo: Rosari, 2006.

O poder da escrita. São Paulo: Rosari, 2011.

MARTINS, Bruno Guimarães. Tipografia popular: potências do ilegível na experiência do cotidiano. São Paulo: Annablume, 2007.

ROCHA, Cláudio. Novo projeto tipográfico. São Paulo: Rosari, 2012.

SAUSSURE, Ferdinand de. Curso de linguística geral. São Paulo: Cultrix, 2006.

VAN LEEUWEN, Theo. Towards a semiotics of typography. In: Information Design Journal + Document Design 14 (2). John Benjamins: 2006.

VAN LEEUWEN, Theo. Typographic meaning. Visual Communication. Vol. 4 no. 2. p. 137-143. SAGE Publications: jun 2005.

WARDE, Beatrice. The Crystal Goblet: Sixteen Essays on Typography, Cleveland: World Pub. Co., 1956. 